\title{
Effect of pre-treatment with transdermal glyceryl trinitrate on myocardial ischaemia during coronary angioplasty
}

\author{
S Ramamurthy, V Mehan, U Kaufmann,V Verin, T F Lüscher, B Meier
}

\begin{abstract}
Objective-In the light of the reported inconsistent anti-ischaemic and antianginal effects of transdermal glyceryl trinitrate, its efficacy and influence on the effects of intracoronary glyceryl trinitrate were examined during coronary angioplasty, which provides a model of controlled, reversible ischaemia.

Design-Double blind, randomised study of the effect of transdermal and intracoronary glyceryl trinitrate on ischaemia during coronary angioplasty.

Patients-40 patients with isolated severe stenosis of the left anterior descending coronary artery.

Interventions-Patients were randomised (double blind) to transdermal gylceryl trinitrate (10 $\mathrm{mg}$ per day) and placebo, starting four to six hours before angioplasty. After 4 one-minute balloon inflations intracoronary glyceryl trinitrate was injected $(0.2 \mathrm{mg})$ and then 4 further oneminute inflations were performed.

Main outcome measures-The time to angina and the time to $>0.2 \mathrm{mV}$ ST shift on surface electrocardiogram (ECG) or intracoronary ECG during the individual

balloon inflation during coronary angioplasty.

(Heart 1996;76:471-476)

Keywords: transdermal glyceryl trinitrate; intracoronary glyceryl trinitrate; angioplasty; myocardial ischaemia.

Balloon inflation during coronary angioplasty commonly produces myocardial ischaemia and angina, and provides a method of producing controlled, reversible ischaemia in humans. The intracoronary, intravenous, or sublingual administration of nitrates is known to reduce these effects. ${ }^{14}$ Transdermal administration of glyceryl trinitrate, which is widely used as antianginal therapy with variable benefits, has not been tested in this setting. We studied the effects of transdermal glyceryl trinitrate on myocardial ischaemia during balloon inflation for coronary angioplasty in a randomised double blind, placebo controlled trial and also the possible influence of transdermal glyceryl trinitrate on the effects of subsequently administered intracoronary glyceryl trinitrate.
\end{abstract} inflations.

Results-These times did not significantly differ during initial inflations between transdermal glyceryl trinitrate (27 (11), 25 (9), and 19 (9) s, respectively) and placebo (34 (11), 30 (8), and 21 (7) s. After intracoronary glyceryl trinitrate, they were significantly prolonged compared with the initial values, without differences between patients with transdermal glyceryl trinitrate $(37(10), 30(8)$, and $23(8) \mathrm{s}$, respectively) or placebo (39 (15), 36 (11), and 28 (12) s). Ischaemic preconditioning was not seen.

Conclusions-Transdermal glyceryl trinitrate (10 mg per day), unlike intracoronary glyceryl trinitrate, did not alleviate the myocardial ischaemia produced by

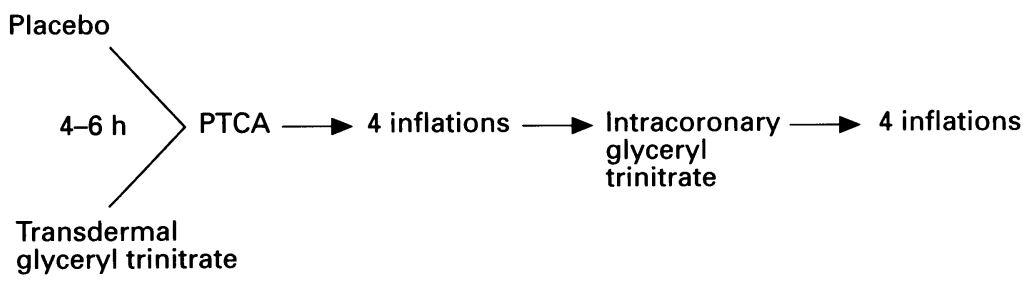

Figure 1 Design of the study. PTCA, coronary angioplasty.

\section{Patients and methods}

Forty consecutive eligible patients were randomised in a double blind fashion to receive either transdermal glyceryl trinitrate (Deponit 10 containing $32 \mathrm{mg}$ of glyceryl trinitrate designed to be released at an average absorption rate of $10 \mathrm{mg}$ per 24 hours) or placebo starting 4-6 hours before coronary angioplasty (fig 1). The patches were applied on a hairfree area on the anterior abdominal wall. Eligible patients had a history of typical angina, reversible ischaemia by non-invasive testing, single vessel coronary artery disease involving the left anterior descending coronary artery (with $\geqslant 70 \%$ stenosis), and normal left ventricular function (ejection fraction $\geqslant 60 \%$ without regional wall motion abnormalities). Patients with known nitrate tolerance, angiographically visible collaterals to the vessel to be dilated, acute myocardial infarction, prior transmural myocardial infarction, left bundle branch block, prior coronary artery bypass surgery, diabetes mellitus, and those who had persistent hypotension on admission were excluded. Those who had received cardioactive drugs in the preceding 24 hours (except aspirin and heparin) or short-acting nitrates in the preceding two hours were also excluded. 
Table 1 Baseline data

\begin{tabular}{llc}
\hline & $\begin{array}{l}\text { Transdermal GTN } \\
(n=19)\end{array}$ & $\begin{array}{l}\text { Placebo } \\
(n=20)\end{array}$ \\
\hline $\begin{array}{l}\text { Age (years) (means (SD)) } \\
\text { Males (n (\%)) }\end{array}$ & $58(8)$ & $57(2)$ \\
Previous antianginal therapy: & $16(84)$ & $17(85)$ \\
$\beta$ Blockers & $8(42)$ & $8(40)$ \\
Calcium antagonists & $6(32)$ & $9(45)$ \\
Long acting nitrates* & $9(48)$ & $10(50)$ \\
GTN & $5(26)$ & $6(30)$ \\
\hline
\end{tabular}

^Stopped $>24 \mathrm{~h}$ before testing. GTN, glyceryl trinitrate.

Informed consent for the study, conforming to the declaration of Helsinki, was obtained from each patient. The study was approved by the institution's human research committee. The baseline characteristics of the two randomised groups are presented in table 1 .

Evaluation before coronary angioplasty included a detailed history, clinical examination, and a standard 12 lead ECG. Coronary angioplasty was performed using the standard techniques. ${ }^{5} \mathrm{~A}$ total of eight balloon inflations of one minute each were made. Sufficient time (minimum of one minute) was allowed between inflations for symptoms and ECG changes to disappear. The inflations made after a satisfactory angiographic result was achieved were low pressure inflations of less than 2 atmospheres, which were sufficient to occlude blood flow in the vessel (confirmed by contrast injections) without injuring the vessel wall. Intracoronary glyceryl trinitrate $(0.2 \mathrm{mg})$ was administered after the fourth inflation, and the fifth inflation was postponed by two minutes (fig 1). Coronary angiography was performed initially, after the fourth balloon inflation, after the last balloon inflation, and as required to assess angiographic results. The angiograms were evaluated by two independent observers to assess the primary success of coronary angioplasty (residual stenosis $<50 \%$ of luminal diameter as a mean of at least two perpendicular projections), collateral flow, and coronary spasm. In 20 patients the diameter of a normal segment of the proximal left anterior descending coronary artery could be measured by quantitative coronary angiography to assess the coronary vasodilatory effect of intracoronary glyceryl trinitrate. Surface ECG (leads I, II, III, and V2) and intracoronary ECG ${ }^{6}$ were recorded before and during the first inflation, during each subsequent inflation and after the last inflation. Mean aortic pressure and mean heart rate were noted before and after each inflation. The following variables were measured for each balloon inflation (1) time to onset of angina from the beginning of inflation (primary variable), (2) time to onset of ST segment shift of $\geqslant 0.2 \mathrm{mV}$ on the surface ECG, (3) time to onset of ST segment shift of $\geqslant 0.2 \mathrm{mV}$ on the intracoronary ECG, (4) maximum ST segment shift on the surface ECG, (5) maximum ST segment shift on the intracoronary ECG.

The variables recorded during the second to fourth and the sixth to eighth balloon inflations were considered for analysis. The ischaemic response to the first inflation is highly variable. ${ }^{7}$ The deflated balloon catheter, by itself, produces variable obstruction to blood flow when first placed across a severe stenosis and, in the setting of a subtotal stenosis, frequently causes ischaemia even before it is inflated. The fifth inflation was performed two minutes after the administration of intracoronary glyceryl trinitrate. This interval could be insufficient to show the maximal effects of intracoronary glyceryl trinitrate.

All variables between the two groups were compared by the Wilcoxon rank-sum test. For within group comparisons we used the paired $t$ test for changes in coronary artery diameter and the Wilcoxon signed-rank test for the other variables. Values are expressed as mean (SD).

\section{Results}

Thirty nine of the 40 randomised patients had a successful coronary angioplasty with a reduction of luminal diameter stenosis from $83(9) \%$ to $14(8) \%$ in the transdermal glyceryl trinitrate group and from $84(7) \%$ to 10 (6) $\%$ in the placebo group. One patient originally randomised to receive transdermal glyceryl trinitrate was excluded because at angiography it was found that the coronary stenosis was not significant and did not warrant coronary angioplasty. Four patients in the transdermal glyceryl trinitrate group and six in the placebo group needed stent implantation for local dissection after balloon inflation. One patient in each group had delayed acute vessel closure leading to myocardial infarction. There were no deaths.

\section{TIME TO ONSET OF ANGINA}

Three patients in the transdermal glyceryl trinitrate group had neither angina nor significant ST changes on ECG during balloon inflations. One in the placebo group had significant ECG changes but no angina during balloon inflations. The time to onset of angina before intracoronary glyceryl trinitrate administration-that is, the average of the values during the second to fourth balloon inflations-was not significantly different with transdermal glyceryl trinitrate and with placebo (27 (11) and $34(11) \mathrm{s}$, respectively). After intracoronary glyceryl trinitrate-that is, during the sixth to eighth balloon inflations, the average time to onset of angina was significantly prolonged within each group ( $37(10)$, and 39 (15) $\mathrm{s}$, respectively), again without a significant difference between the groups (fig 2 ).

TIME TO ONSET OF SIGNIFICANT ST SHIFT ON SURFACE ECG

The time to onset of significant ST shift on surface ECG was not significantly different in the transdermal glyceryl trinitrate and placebo groups either before intracoronary glyceryl trinitrate (25 (9) and 30 (8) s, respectively) or after intracoronary glyceryl trinitrate (30 (8), and $36(11) \mathrm{s})$. As with time to angina, after intracoronary glyceryl trinitrate, this variable significantly increased in both groups alike (fig 3). 

angina (mean $(S D)$ ). during balloon inflations. TGTN, transdermal glyceryl trinitrate; IC GTN, intracoronary glyceryl trinitrate. Before IC GTN = mean of values of second to fourth inflations; after IC GTN

$=$ mean of values of sixth to eighth inflations.

Figure 3 Time to onset of $\geqslant 0.2 \mathrm{mVST}$ shift on surface ECG (mean (SD)) during balloon inflations. See legend to fig 2 for abbreviations.
Figure 2 Time to onset of
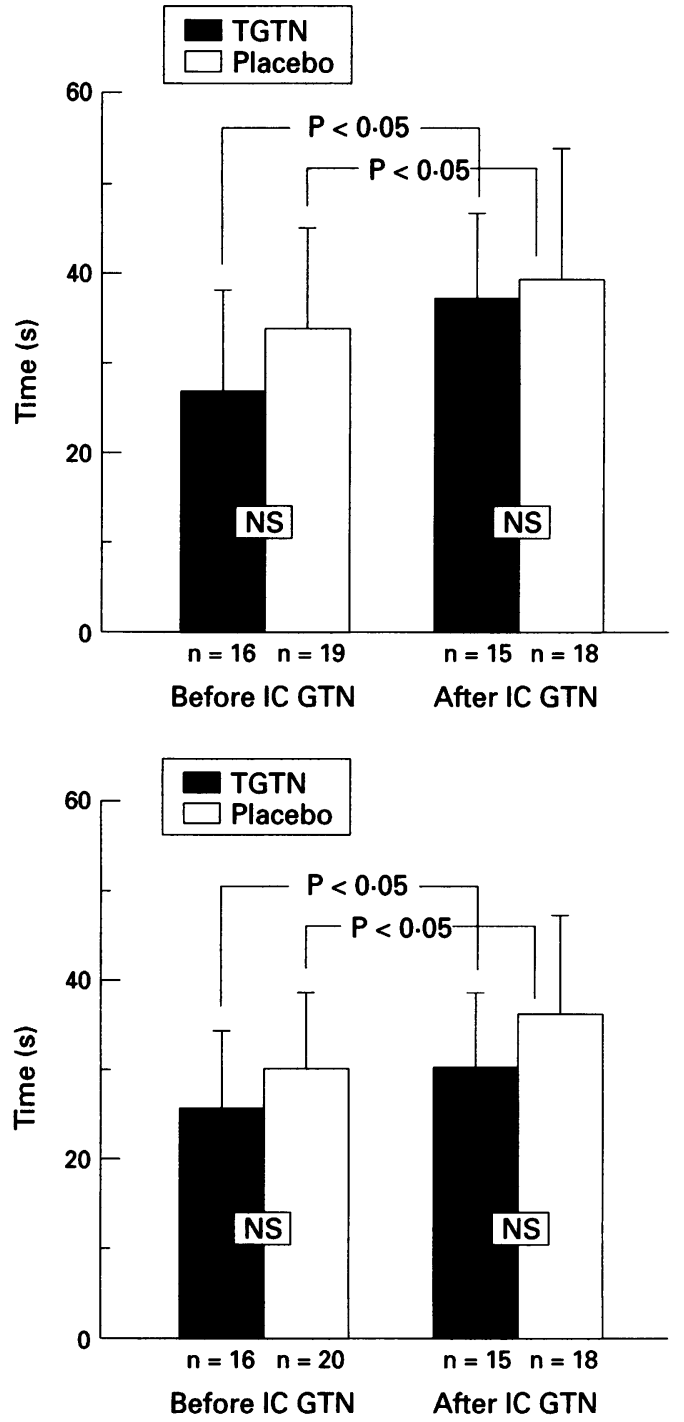

TIME TO ONSET OF SIGNIFICANT ST SHIFT ON INTRACORONARY ECG

The results were similar to those seen with the surface ECG. The groups did not differ significantly in the time to onset of significant ST shift either before intracoronary glyceryl trinitrate (19 (9) s with transdermal glyceryl trinitrate, and $21(7) \mathrm{s}$ with placebo) or after intracoronary glyceryl trinitrate $(23$ (8) and 28 (12) s, respectively). Within both groups, however, this interval was significantly pro-

Figure 4 Time to onset of $\geqslant 0.2 \mathrm{mVST}$ shift on intracoronary ECG (mean (SD)) during balloon inflations. See legend to fig 2 for abbreviations.

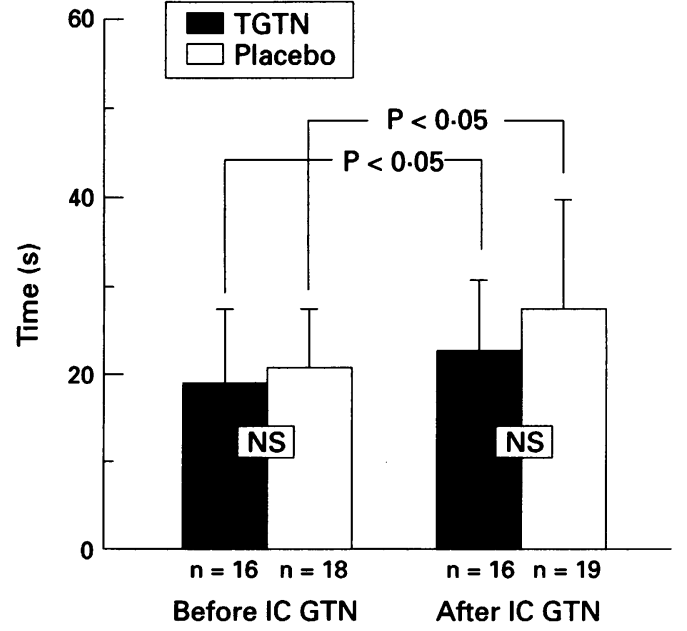

Table 2 Maximum ST segment shift ( $m V$ ) on surface ECG during balloon inflation (mean SD))

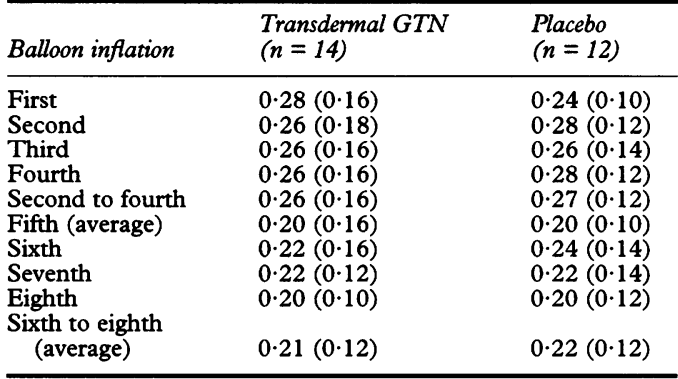

Table 3 Maximum ST segment shift ( $m V$ ) on intracoronary ECG during balloon inflation (mean (SD))

\begin{tabular}{lll}
\hline Balloon inflation & $\begin{array}{l}\text { Transdermal GTN } \\
(n=14)\end{array}$ & $\begin{array}{l}\text { Placebo } \\
(n=13)\end{array}$ \\
\hline First & $0.72(0.53)$ & $0.74(0.59)$ \\
Second & $0.76(0.61)$ & $0.72(0.56)$ \\
Third & $0.82(0.62)$ & $0.76(0.58)$ \\
Fourth & $0.80(0.64)$ & $0.82(0.62)$ \\
Second to fourth & $0.79(0.62)$ & $0.77(0.60)$ \\
Fifth (average) & $0.66(0.58)$ & $0.69(0.49)$ \\
Sixth & $0.69(0.62)$ & $0.73(0.59)$ \\
Seventh & $0.71(0.60)$ & $0.72(0.56)$ \\
Eighth & $0.68(0.63)$ & $0.74(0.58)$ \\
Sixth to eighth & & \\
$\quad$ (average) & $0.69(0.61)$ & $0.73(0.57)$ \\
\hline
\end{tabular}

longed after intracoronary glyceryl trinitrate (fig 4).

\section{MAXIMUM ST SHIFT DURING BALLOON}

INFLATION

The maximum ST shift on surface ECG with transdermal glyceryl trinitrate was not significantly different compared with placebo. Nor was it significantly influenced by intracoronary glyceryl trinitrate. The ST shift in the intracoronary ECG was larger than in the surface ECG (as observed earlier ${ }^{8}$ ) but it was not changed significantly by either transdermal or intracoronary glyceryl trinitrate (tables 2 and 3).

\section{CORONARY ARTERY DIAMETER}

Compared with baseline values the coronary artery diameter measured in a normal segment of the proximal left anterior descending coronary artery increased significantly after intracoronary glyceryl trinitrate in patients who had received transdermal glyceryl trinitrate as well as in those who had received placebo (table 4). The extent of change in coronary diameter after intracoronary glyceryl trinitrate was not significantly different in the two groups.

BLOOD PRESSURE AND HEART RATE

Mean aortic blood pressure and heart rate were not different in the two study groups either before or after intracoronary glyceryl trinitrate. There was no significant difference

Table 4 Proximal LAD diameter ( $\mathrm{mm}$ ) (mean (SD))

\begin{tabular}{lll}
\hline & $\begin{array}{l}\text { Transdermal GTN } \\
(n=9)\end{array}$ & $\begin{array}{l}\text { Placebo } \\
(n=11)\end{array}$ \\
\hline Pre-PTCA & $3.90(0.96)$ & $3.99(0.84)$ \\
Post-IC GTN & $4 \cdot 12(0.82)^{\star}$ & $4 \cdot 31(0.83)^{\star}$ \\
Post-PTCA & $4.05(0.80)$ & $4 \cdot 23(0.98)$ \\
\hline
\end{tabular}

$\mathrm{LAD}$, left anterior descending coronary artery; PTCA, percutaneous transluminal coronary angioplasty; IC GTN, intracoronary glyceryl trinitrate. ${ }^{\star} P<0.05$ compared with prePTCA values. 


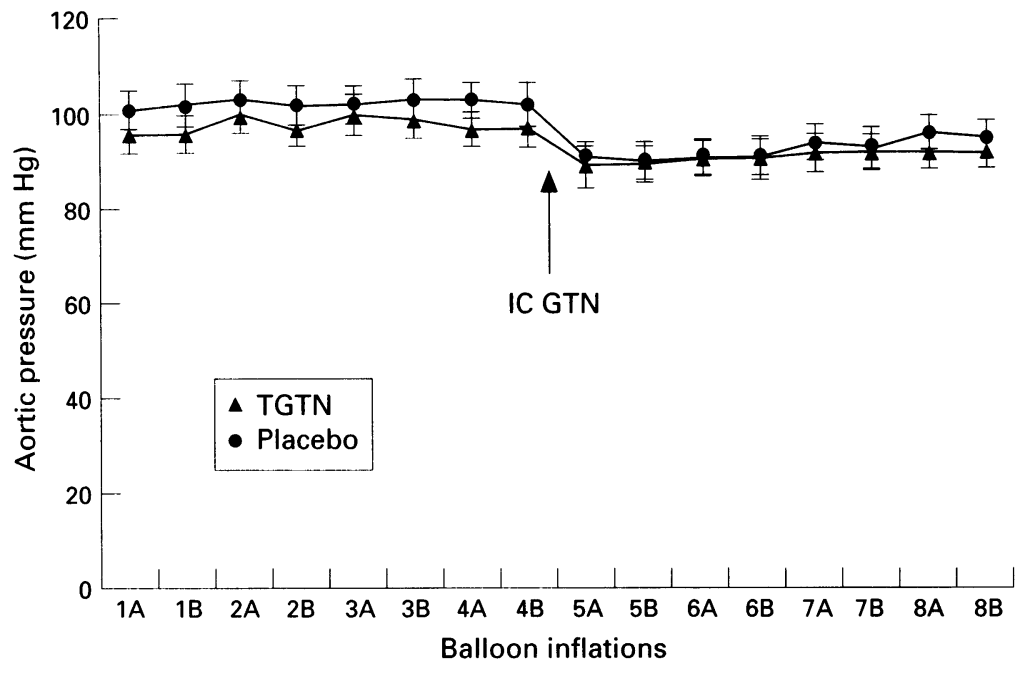

Figure 5 Aortic pressure (mean (SE)) before (A) and after (B) each balloon inflation.

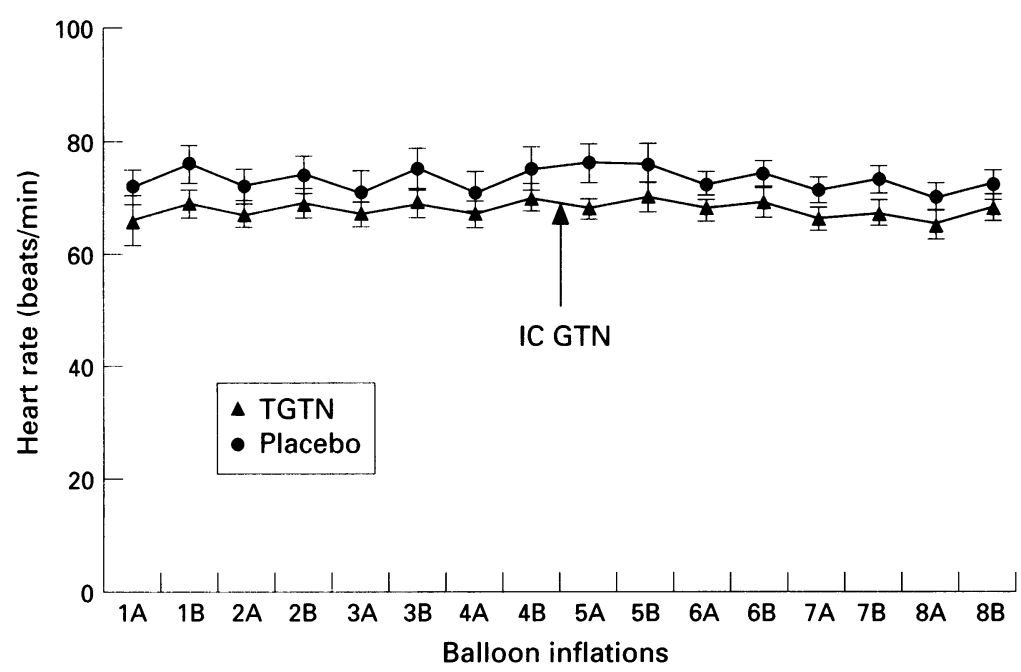

Figure 6 Heart rate (mean (SE)) before $(A)$ and after $(B)$ each balloon inflation.

in these variables after each balloon inflation compared with the values before inflation. A slight and similar decrease in blood pressure was seen in both groups after intracoronary injection of glyceryl trinitrate (figs 5 and 6).

Table 5 Time (s) to angina during balloon inflation (mean (SD))

\begin{tabular}{lll}
\hline Balloon inflation & $\begin{array}{l}\text { Transdermal GTN } \\
(n=16)\end{array}$ & $\begin{array}{l}\text { Placebo } \\
(n=19)\end{array}$ \\
\hline First & $31(15)$ & $29(15)$ \\
Second & $25(13)$ & $34(13)$ \\
Third & $28(12)$ & $34(11)$ \\
Fourth & $28(13)$ & $33(16)$ \\
Fifth & $37(14)$ & $41(13)$ \\
Sixth & $34(10)$ & $39(17)$ \\
Seventh & $37(13)$ & $37(14)$ \\
Eighth & $39(11)$ & $41(17)$ \\
\hline
\end{tabular}

Table 6 Time (s) to $\geqslant 0.2 \mathrm{mV} \mathrm{ST} \mathrm{segment} \mathrm{shift} \mathrm{in}$ surface ECG during balloon inflation (mean (SD))

\begin{tabular}{lll}
\hline Balloon inflation & $\begin{array}{l}\text { Transdermal GTN } \\
(n=16)\end{array}$ & $\begin{array}{l}\text { Placebo } \\
(n=20)\end{array}$ \\
\hline First & $28(13)$ & $30(10)$ \\
Second & $24(10)$ & $31(9)$ \\
Third & $26(9)$ & $29(9)$ \\
Fourth & $26(12)$ & $28(8)$ \\
Fifth & $34(11)$ & $39(12)$ \\
Sixth & $29(8)$ & $35(8)$ \\
Seventh & $30(9)$ & $35(13)$ \\
Eighth & $31(9)$ & $36(13)$ \\
\hline
\end{tabular}

Table 7 Time $(s)$ to $\geqslant 0.2 \mathrm{mVST}$ segment shift in intracoronary ECG during balloon inflation (mean (SD))

\begin{tabular}{lll}
\hline Balloon inflation & $\begin{array}{l}\text { Transdermal GTN } \\
(n=16)\end{array}$ & $\begin{array}{l}\text { Placebo } \\
(n=19)\end{array}$ \\
\hline First & $17(8)$ & $20(10)$ \\
Second & $19(10)$ & $21(6)$ \\
Third & $16(5)$ & $21(9)$ \\
Fourth & $18(9)$ & $21(8)$ \\
Fifth & $24(12)$ & $28(11)$ \\
Sixth & $22(8)$ & $27(12)$ \\
Seventh & $22(8)$ & $26(11)$ \\
Eighth & $23(8)$ & $28(13)$ \\
\hline
\end{tabular}

ISCHAEMIC PRECONDITIONING

In both the study groups successive balloon inflations before injection of intracoronary glyceryl trinitrate and after it did not increase tolerance to ischaemia (preconditioning) (tables 2 and 3 and 5-7).

\section{Discussion}

Over the years the use of transdermal glyceryl trinitrate as an anti-anginal agent has raised several controversies. The problems of variable drug absorption, need for frequent dosing, and fluctuating plasma drug concentrations were overcome by replacing glyceryl trinitrate ointment with the transdermal patch system. ${ }^{9}$ The daily continuous use of such patches, however, led to the problem of nitrate tolerance which was not eliminated by increasing the glyceryl trinitrate dosage ${ }^{10}$ but was reduced by intermittent patch administration. ${ }^{11}$ Recent data, however, suggest that rebound ischaemia may result from intermittent administration. ${ }^{12}$ Further, the effects of transdermal glyceryl trinitrate on exerciseinduced myocardial ischaemia and on symptomatic anginal attacks seem to be unconnected. Though exercise-induced ischaemia improved in several studies, evidence that it reduces the frequency of anginal attacks is not convincing. ${ }^{13}$ Our observations in the setting of coronary angioplasty, a model of controlled reproducible ischaemia, accentuate the controversy surrounding the use of transdermal glyceryl trinitrate in patients with coronary artery disease.

We found that the application of the transdermal glyceryl trinitrate patch at a dose of 10 mg per day 4-6 hours before coronary angioplasty did not influence either the time to onset of angina nor the magnitude or the time to onset of ischaemic changes on surface or intracoronary ECGs during balloon inflation. On the other hand, the administration of intracoronary glyceryl trinitrate significantly prolonged the time to onset of angina as well as the time to onset of ischaemic changes on both surface and intracoronary ECGs. These effects of intracoronary glyceryl trinitrate were neither augmented nor reduced by prior administration of transdermal glyceryl trinitrate.

The beneficial effects of glyceryl trinitrate administered by the intracoronary, intravenous, or sublingual routes during coronary angioplasty has been demonstrated in earlier studies. ${ }^{1.4}$ Transdermal glyceryl trinitrate including the system used in our study has been shown to be effective in reducing exer- 
cise-induced ischaemia. ${ }^{14}$ This makes the lack of benefit of transdermal glyceryl trinitrate in the context of coronary angioplasty intriguing. Possible explanations include (1) suboptimal drug dose, (2) inappropriate timing of administration, (3) onset of rapid nitrate tolerance, (4) absence of significant haemodynamic changes after transdermal glyceryl trinitrate administration, (5) activation of the sympathetic and aldosterone systems by transdermal glyceryl trinitrate, and (6) the mode by which ischaemia is induced during balloon inflation.

The dose of transdermal glyceryl trinitrate used in our study (absorption rate of $10 \mathrm{mg} / 24$ h) has been commonly and effectively used in earlier studies and would be deemed adequate for anti-ischaemic effect. ${ }^{10-14}$ The interval of 4- 6 hours between application of the glyceryl trinitrate patch and the angioplasty procedure in our study allowed sufficient time for drug action. After transdermal administration plasma concentrations of glyceryl trinitrate peak at $2-4$ hours and attain a steady state thereafter. ${ }^{15}$ Nitrate tolerance is more common and occurs more rapidly with treatments that produce steady plasma drug concentrations. However, such tolerance usually occurs beyond eight hours of initial application of a transdermal glyceryl trinitrate patch. ${ }^{16-19}$ In our study, no significant effect on blood pressure or heart rate was noted after transdermal glyceryl trinitrate administration. After intracoronary glyceryl trinitrate, an insignificant fall in blood pressure was noted. It could be argued that the effectiveness of intracoronary glyceryl trinitrate as opposed to transdermal glyceryl trinitrate was related to this difference. The fact that plasma concentrations were not measured turned out to be a considerable flaw of the study. We cannot exclude the possibility that low plasma concentrations after transdermal application accounted for the lack of effect.

On the other hand, the influence of the catecholamine and renin-aldosterone activity on the effect of transdermal glyceryl trinitrate may be responsible for the observed lack of benefit with transdermal glyceryl trinitrate. An earlier study has shown that in subjects with higher catecholamine and renin-aldosterone activity, transdermal glyceryl trinitrate confers little or no benefit even against exercise induced ischaemia. ${ }^{20}$ Such activation may occur as early as 90 minutes after nitrate administration. ${ }^{21}$ Although we did not measure catecholamine or renin aldosterone activity in our patients, it is reasonable to expect that during coronary angioplasty, such activity might be high enough to interfere with the antiischaemic effect of transdermal glyceryl trinitrate.

Another plausible explanation could be the mode of ischaemia production during balloon inflation. In exercise-induced ischaemia there is a gradual alteration of the balance between myocardial oxygen demand and supply, whereas the ischaemia that occurs during balloon inflation results from rapid occlusion of the coronary artery. It is possible that the relief of ischaemia that is produced so rapidly requires higher or rapidly rising plasma concentrations of glyceryl trinitrate or a more potent glyceryl trinitrate action. It is known that although transdermal glyceryl trinitrate improves exercise-induced ischaemia, this improvement is not maximal and further improvement occurs when sublingual glyceryl trinitrate is additionally administered. ${ }^{11}$ This suboptimal effect of transdermal glyceryl trinitrate may be related to the lower or more slowly rising plasma drug concentrations compared with intravenous or sublingual administration or to a differing ratio of the two active dinitrate metabolites of glyceryl trinitrate (the ratio of 1.2 and 1.3 dinitroglyceryl metabolites varies as a function of the route of administration) and may explain its reduced effect in the setting of coronary angioplasty. ${ }^{91522}$ Therefore, it is possible that the model of ischaemia induced by balloon inflation during coronary angioplasty is not always comparable to models of exercise-induced ischaemia. Nevertheless, our data suggest that pretreatment of patients with glyceryl trinitrate patches before coronary angioplasty cannot be recommended.

An interesting corollary from our study is the absence of evidence for ischaemic preconditioning during successive balloon inflations. Ischaemic preconditioning is not a established phenomenon in humans and our criteria for control inflations (exclusion of the first and the fifth balloon inflations) and the elimination of patients with pre-existing angiographic collaterals are more rigid than in other studies demonstrating this phenomenon. ${ }^{23} 25$ Absence of preconditioning under similar conditions has recently been suggested. ${ }^{26}$

1 Erbel R, Schreiner G, Henkel B, Pop T, Meyer J. Improved ischemic tolerance during percutaneous transluminal coronary angioplasty by intracoronary injection of nitroglycerin. Z Kardiol 1983;77(suppl 3):71-3

2 Doorey AJ, Mehmel HC, Schwartz FX, Kübler W Amelioration by nitroglycerin of left ventricular ischemia induced by percutaneous transluminal coronary angioinduced by percutaneous transluminal coronary angioplasty: assessment by haemodynamic variables and

3 Finci L, Meier B, Ruiz J, Urban P, Steffenino G, Divernois $\mathrm{J}$, et al. Nitrates before coronary angioplasty: sublingual versus intracoronary administration (abstract). Eur Heart $\mathcal{f}$ versus intracoronary

4 Lewis BS, Halon DA, Merdler A, Makhoul N, Afriat S, Schneeweiss A. Usefulness of intracoronary isosorbide dinitrate in alleviating myocardial ischemia during coronary balloon angioplasty. Eur Heart $\mathcal{F}$ 1992;13:1534-9.

5 Meier B. Technique of coronary angioplasty. In: Meier B, ed. Interventional cardiology. Toronto: Hogrefe \& Huber, 1990:45-70

6 Meier B, Rutishauser W. Coronary pacing during percutaneous transluminal coronary angioplasty. Circulation 1985;71:557-61.

7 Perry RA, Seth A, Hunt A, Smith SCH, Westwood, Woolsgar $\mathrm{N}$, et al. Balloon occlusion during coronary angioplasty as a model of myocardial ischemia: reproangiopilasty of sequential inflations. Eur Heart $f$ 1989;10:791-800

8 Pande AK, Meier B, Urban P, Moles V, Dorsaz PA, Favre $\mathrm{J}$. Intracoronary electrocardiogram during coronary angioplasty. Am Heart f 1992;124:337-41. Zeller FP, Klamerus KJ. Controversies in the use of transdermal nitroglycerin systems. Clin Pharm 1987;6:605-16. Steering Committee, Transdermal Glyceryl Trinitrate Cooperative Study. Acute and chronic antianginal efficacy of continuous twenty-four-hour application of transcacy of continuous twenty-four-hour application of trans-

11 de Milliano PA, Koster RW, Bär FW, Jannsen J, de Cock C, Schelling A, et al. Longterm efficacy of continuous and intermittent use of transdermal nitroglycerin in stable angina pectoris. Am f Cardiol 1991;68:857-62.

12 Freedman SB, Daxini BV, Noyce D, Kelly DT Intermittent transdermal nitrates do not improve ischemia in patients taking beta-blockers or calcium antagonists: Potential role of rebound ischemia during 
the nitrate-free period. $\mathcal{F} \mathrm{Am}$ Coll Cardiol 1995;25: 349-55.

13 Akhras F, Hellestrand K, Whalley D, Jackson G. Efficacy of intermittent (eight hours off) transdermal nitrate therapy in stable angina. Int $\mathcal{F}$ Cardiol 1994;43:251-6.

14 Greco R, d'Alterio D, Schiattarella M, Boccia A, Greco L, Marsico F. Efficacy of a new transdermal nitroglycerin patch (Deponit 10) for stable angina pectoris. $\mathrm{Am} \mathcal{f}$ Cardiol 1988;61:44E-51E.

15 Nakashima E, Noonan PK, Benet LZ. Transdermal bioavailability and first-pass metabolism: A preliminary evaluation with nitroglycerin. $\mathcal{F}$ Pharmacokinet Biopharm uation with nitroglycerin. F Pharmacokinet Biopharm 1987;15:423-37.

16 Abrams J. Interval therapy to avoid nitrate tolerance: Paradise regained? Am f Cardiol 1989;64:931-4.

17 Parker JO. Nitrate therapy in stable angina pectoris. $N$ Engl F Med 1987;316:1635-42.

18 Reichek N, Priest C, Zimrin D, Chandler T, St Sutton MJ. Antianginal effects of nitroglycerin patches. Am $\mathcal{F}$ Cardiol 1984;54:1-7.

19 Thadani U, Hamilton SF, Olson E, Anderson J, Voyles W, Prasad R, et al. Transdermal nitroglycerin patches in angina pectoris. Ann Intern Med 1986;105;485-92.

20 Muiesan ML, Agabiti-Roseli E, Romanelli G, Beschi M, Catellano $M$, Cefis $M$, et al. Transdermal nitroglycerin efficacy in patients with chronic stable angina pectoris as related to sympathetic and renin-angiotensin-aldosterone activity. Eur Heart f 1992;13:15-21

21 Noll G, Wenzel RR, de Marchi S, Lüscher TF. Differential effects of nitrates and captopril on the activity of the sympathetic nervous system (abstract). Eur Heart $\mathcal{f}$ 1995;16 (suppl) 34

22 Todd PA, Goa KL, Langtry HD. Transdermal nitroglycerin (glyceryl trinitrate): A review of its pharmacology and therapeutic use. Drugs 1990;40:880-902.

23 Deutsch E, Berger $M$, Kussmaul WG, Hirshfeld JW, Herrmann CH, Laskey WK. Adaptation to ischemia during percutaneous transluminal coronary angioplasty: clinical, haemodynamic and metabolic features. Circulation 1990;82:2044-51.

24 Cribier A, Korsatz L, Konong R, Rath P, Gamra H, Stix G et al. Improved myocardial ischemic response and et al. Improved myocardial ischemic repetitive coronary occlusion during angioplasty: a prospective study. $\mathcal{F}$ Am Coll Cardiol 1992;20:578-86.

25 Tomai F, Crea F, Gaspardone A, Versaci F, Esposito C, Chiariello $\mathrm{L}$, et al. Mechanisms of cardiac pain during coronary angioplasty. $f \mathrm{Am}$ Coll Cardiol 1993;22: 1892-6.

26 Dupouy P, Gschwind H, Pelle G, Aptecar E, Hiltinger L, El Ghalid A, et al. Repeated coronary artery occlusions during routine balloon angioplasty do not induce myocardial preconditioning in humans. $\mathcal{f} \mathrm{Am}$ Coll Cardiol 1996;27:1374-80. 